(2) Open Access Full Text Article

ORIGINALRESEARCH

\title{
Impact of Service Quality on In-Patients'
}

\section{Satisfaction, Perceived Value, and Customer} Loyalty: A Mixed-Methods Study from a Developing Country

\author{
Nhi Xuan Nguyen' \\ Khoa Tran (D) \\ Tuyet Anh Nguyen ${ }^{2}$
}

'Faculty of Business Administration, Nguyen Tat Thanh University, Ho Chi Minh City, Vietnam; ${ }^{2}$ Department of Business, Minerva University, San Francisco, CA, USA
Correspondence: Khoa Tran Faculty of Business Administration, Nguyen Tat Thanh University, 300A Nguyen Tat Thanh, Ward 13, District 4, Ho Chi Minh City, Vietnam

Tel +84562 688998

Email anhkhoatran3007@gmail.com
Purpose: Recent literature on healthcare quality demands more contextualized and patientperspective research, as models from developed countries are not suitable for developing countries. Moreover, research on private healthcare services in Vietnam has long been underestimated by academia, but it has significant economic and commercial value. Hence, this study explores the dimensions of service quality in private healthcare and how they impact in-patient satisfaction, perceived value, and customer loyalty in Vietnam.

Methods: This mixed-method study had a sample size of five inpatients for the qualitative phase and 368 inpatients for the quantitative phase from hospitals in Vietnam. The qualitative analysis explores service quality dimensions in private healthcare and incorporates them with the literature to develop a conceptual model. The quantitative phase tests the relationship between each construct in the conceptual model via structural equation modeling.

Results: The four dimensions of service quality were emotion, function, social influence, and trust. Most of these dimensions have a significant impact on customer perceived value and satisfaction. However, emotion does not significantly influence customer perceived value, and function does not considerably impact customer satisfaction. In addition, social influence is an underrepresented variable in the service quality literature, but it has the most substantial impact on customer perceived value and customer satisfaction. The quantitative results also confirm that customer satisfaction and customer perceived value significantly impact customer loyalty (word-of-mouth and revisit intention); however, customer perceived value does not significantly impact customer satisfaction.

Conclusion: The study suggests that private healthcare providers and the government in Vietnam should allocate resources to improve service quality. Practitioners should invest in social branding and e-services to reach out to their customers. Future research should focus on a cost-benefit analysis and compare the effectiveness of service quality dimensions on customer behavioral intention.

Keywords: customer perceived value, customer satisfaction, private healthcare, revisit intention, service quality, word-of-mouth

\section{Background}

Private healthcare services are a crucial part of the global health system. Private healthcare providers have increasingly become involved in health systems, both in scale and scope, because of their potential. For instance, privately funded services stimulate equity in the society. Since clients from the middle and wealthy classes 
prefer to pay more for the private healthcare service to meet their requirements and higher service expectations, private healthcare providers satisfy those who can afford it and facilitate the public healthcare system to focus on those who cannot afford it. Additionally, private healthcare providers' involvement in healthcare fosters accessibility to health services among people living in rural areas. ${ }^{1}$ In addition, the private healthcare system shoulders the fiscal burden with governmental bodies when finance for maintenance, rehabilitation, and new investment in high-quality equipment. Recently, the private healthcare system has reiterated its role by joining the battle with a pandemic crisis. Amid the Covid-19 pandemic, many national healthcare systems worldwide have been overwhelmed. To alleviate the grave challenges and deal with pertinent implications, governments collaborate with private healthcare providers to enhance proactive and collaborative public-private partnerships. Hence, it is crucial to nurture a high-quality and sustainable private healthcare system in all nations.

Health care administrators and physicians have long strived to provide high-quality services. However, many studies have pointed out the healthcare literature lacks patient-centered design and localized research. Scholars have indicated that healthcare service providers should follow the patient-centered design to improve patient experiences and the value of care because it can help healthcare managers and policymakers make investments in the right element. However, a recent study pointed out that while employees consider the quality of a specific service element to be too low, patients do not always perceive it as a big problem. ${ }^{2}$ Besides, prior research usually deploys quantitative methods, such as SEM-PLS, when studying service quality and behavioral intention. As service quality dimensions may differ according to surveyed contexts, quantitative analysis alone is not sufficient to make practical recommendations for healthcare service providers. $^{3}$ A recent systematic review recognizes that previous papers on measuring the quality of healthcare primarily utilized models from developed countries' origin. This study suggests that research in developing countries should construct a model for measuring the quality of healthcare services, as models in developed nations might not be appropriate in developing contexts. With regard to research on patient experience of service quality in developing countries, there is little research in Vietnam. The majority is in Iran, Pakistan, Bangladesh, and India. ${ }^{4}$
Hence, the context of our research is in Vietnam to bridge the literature gap.

In Vietnam, private health services have coexisted with public health services for over 20 years, but their scale and size are still small compared to their public counterparts. However, private healthcare services have the potential to bring about profitable business opportunities and economic growth. As stated by the Ministry of Health, when they implement a series of preferential policies to invest in medical examination and treatment, a considerable increase in private hospitals and hospitals with foreign investment occurs accordingly. Moreover, according to the Law on Corporate Income Tax since 2009, special tax incentives for businesses operating in the healthcare industry will remove many obstacles in private health activities. As the government has assisted private medical institutions with their supply side challenges, private healthcare providers' current goal is to redirect patients from the public sector into their sector.

Vietnamese residents still prefer state-funded healthcare providers, leading to an overload in this sector, but a tragic scene in the other. One of the rationales is the higher price of private health services in Vietnam. However, researchers have stated that price is not a primary determinant when choosing private hospitals. ${ }^{5}$ Instead, inpatients in emerging markets rely on convenience, turnaround time, specialties, reputation, and word-of -mouth in their decision-making process of private healthcare services. A previous study has also shown that the clinic's delivery methods, such as customer-oriented care and amenities, might be more important than perceptions of physician's technical skills and treatment methods. Therefore, service quality in health care might become a critical factor in inpatients' choice of hospitals. It also indicated that technical quality across a range of private providers in Vietnam seems to be inferior to that of public institutions, although public healthcare services are also of a low standard. ${ }^{6}$

There are two recent studies on service quality and customer loyalty in Vietnam. However, both studies have focused on public institutions. The first study recognizes that total quality management has a significant impact on in-patient's perceived service quality and patient satisfaction, leading to patient loyalty in the public sector. In the limitation section, the authors question whether these relationships exist in the private healthcare context. ${ }^{7}$ The other article, which researched the perceived crowding on patient satisfaction in public institutions, also 
acknowledges in its discussion that Vietnamese patients have different preferences for service quality between private and public healthcare. Public and private healthcare institutions also have different business models and business selling points; hence, the strategy for public institutions might not be transferable to private healthcare. ${ }^{8}$ Thirdly, in terms of methodology, these two articles use SEM to measure patients' perceptions of service quality, customer satisfaction, and customer loyalty. All these variables are subjective; therefore, quantitative methods may not reflect the perception or view of patients thoroughly. Therefore, there is a need for qualitative methods to comprehensively explore the demand for inpatients. From the practical contribution, the novelty of this research lies in contextualization, as understanding the context is likely to assist in making more practical and effective policies. From the theoretical contribution, this research will enrich the recent literature on the private sector, where profitdriven institutions aim to enhance their service quality to boost profits rather than lower costs and make it affordable in the public sector.

\section{Literature Review}

In 1985, scholars defined service quality as the comparison between customers' expectations and their perceived service performance. ${ }^{9}$ In the healthcare context, the main dimensions of service quality are (1) functional quality (or process quality), defined as the way healthcare providers deliver healthcare services to patients; and (2) technical quality (or outcome quality), related to the accuracy of medical procedures and diagnoses. ${ }^{10}$ As most patients do not have enough knowledge to assess the technical side, our research concentrates on functional quality. Customer perceived value refers to customers' assessment of the utility of products and services, which hinge upon their perceptions of what they give and what they receive in return. ${ }^{11}$ Researchers normally operationalize customers' perceptions of service quality in the healthcare context. ${ }^{12}$ In other words, CPV in healthcare is patients' assessment of service quality before deciding to use the healthcare service. Meanwhile, customer satisfaction pertains to customers' comparison between expectations and the actual performance of services experienced by patients. ${ }^{13}$ Therefore, researchers distinguish service quality, CPV, and customer satisfaction based on the patients' evaluation stage. Service quality provides the criteria that patients use to evaluate hospital services. CPV appears when the patients use the criteria to assess service quality before usage based on external information such as friends' recommendations or perceived cost and benefit. Customer satisfaction then occurs after usage when patients evaluate whether the quality of service achieves their perception of service quality.

To measure service quality, scholars have also developed the SERVQUAL model to help service providers identify and effectively improve their service delivery. The SERVQUAL model categories service quality into five dimensions: tangibility, reliability, responsiveness, assurance, and empathy. ${ }^{14}$ This research paved the way for scholars to examine the impacts of service quality from customers' perspectives. Subsequently, the modified SERVQUAL model in healthcare settings has become widely used to analyze patient's perceptions of service quality. When researchers adopt this model in the healthcare context, they define service quality as medical services that simultaneously maximize inpatients' welfare and balance the expected benefits and losses during the treatment process. The extent to which healthcare service quality meets inpatients' demand depends on the service outcome, service process, and physical environment. ${ }^{15}$ However, scholars have also pointed out the limitations of the SERVQUAL model in the healthcare context. Two significant problems are that this patient-centered approach fails to examine the patient's evaluation of the outcome and the interaction between service users and service providers. ${ }^{16}$ Secondly, there is little research on where scholars investigate the service quality dimensions from Vietnamese inpatients and in Vietnam's healthcare system. These literature gaps lead the authors to carry out a qualitative review with inpatients, with the aim of determining the dimensions of service quality from the inpatients' perspectives in the healthcare context of Vietnam.

After the qualitative phase, this study re-categorizes healthcare service quality into four dimensions: (1) emotion, (2) function, (3) trust, and (4) social influence. The researchers defined the scope of these dimensions based on previous studies. First, emotional value is the feeling or affective state generated by consumption experience. This study also stated that promoting positive or mitigating negative emotional states in emotional value plays a vital role in personal health. ${ }^{17}$ Secondly, functional value refers to economic benefit and the functionality provided by a product or service. In healthcare, functional value illustrates how patients' consumption of private healthcare services helps them achieve good health. Third, trust relates to the confidence of inpatients in 
medical staff's professional ability and the reliability of medical service. ${ }^{18}$ Finally, social influence is patients' perceptions of service providers' reputation through patients' close networks, social media, and patients' communication with medical experts. It also includes service providers' contributions to society via offline or digital spaces, such as medical webinars or pro bono services. ${ }^{19,20}$

Regarding CPV, although the perception of customerrelated service quality is very subjective, existing empirical studies have pointed out that companies with high customer perceived value have more competitive advantages than their competitors and are more likely to retain customers. While previous empirical studies have shown that emotional value and social influence significantly affect CPV, these findings are in non-medical contexts. ${ }^{21,22}$ Hence, to further understand the influence of service quality on CPV, the study posits the following hypotheses:

H1a: Function positively affects Customer perceived value.

H2a: Emotion positively affects Customer perceived value.

H3a: Social influence positively affects Customer perceived value.

H4a: Trust positively affects Customer perceived value.

In healthcare, in-patient satisfaction is a continuous evaluation based on the stimuli related to the stages before and after customers' use of medical services. If healthcare providers can exceed the expectations of their inpatients in the long run, they can achieve sustainable success in the long run. ${ }^{15} \mathrm{In}$ recent healthcare research, most empirical studies have pointed out that service quality positively influences customer satisfaction. For instance, scholars investigating inpatients from eight private hospitals in Tehran, Iran, showed a causal link between service quality and overall satisfaction in private hospitals. ${ }^{23}$ In online life insurance, social influence also strongly connects with customer satisfaction. ${ }^{24}$ Therefore, authors formulate hypotheses as follows:

H1b: Function positively affects Customer satisfaction.

H2b: Emotion positively affects Customer satisfaction.

H3b: Social influence positively affects Customer satisfaction.
H4b: Trust positively affects Customer satisfaction.

Numerous studies on the relationship between CPV and customer satisfaction have shown that a higher CPV leads to higher customer satisfaction. Smith and Swinehart found that consumers' perceptions of quality play a vital role in determining the satisfaction level in healthcare. ${ }^{25}$ Other empirical studies in the medical context also support this finding, such as health insurance products in Malaysia and medical tourism services. ${ }^{26,27}$ Thus, the following hypotheses are proposed in the Vietnamese private healthcare industry:

H5: Customer perceived value positively affects Customer satisfaction.

Customer loyalty occurs when the customer is willing to repeat purchases of products to build a stronger relationship with the provider. ${ }^{28}$ According to Yim et al, customer loyalty makes the customer choose a supplier as their preference and resist all persuasion by its competitors. ${ }^{29}$ Through the lens of private healthcare inpatients, this research focuses on two main aspects of customer loyalty. They are customers' revisit intention (customer intention to visit to use the services of the private healthcare units again) and word-of-mouth behavior (people's sharing experiences both orally and electronically).

Existing literature has explored the positive effects of CPV on customer loyalty. Caruana and Fenech conducted a postal survey among dental inpatients and found that CPV, directly and indirectly, affects customer loyalty. ${ }^{30}$ Data collected from 515 hospitalized inpatients of 2 tertiary hospitals in India, ${ }^{31}$ and the study on the association between CPV and in-patient loyalty in Turkish public university hospitals also reach the same conclusion. ${ }^{32}$ Thus, researchers posit that:

H6a: Customer perceived value positively affects Revisit intention.

H6b: Customer perceived value positively affects the Word-of-mouth.

In addition to $\mathrm{CPV}$, the literature has confirmed the relationship between customer satisfaction and customer loyalty in the healthcare context. For example, data from 40 private hospitals in Hyderabad, India, found that inpatient satisfaction is directly related to inpatients' loyalty to the hospital. ${ }^{33}$ Investigating six private hospitals in Pakistan, scholars also proposed that in-patient satisfaction 
is positively related to in-patient loyalty. ${ }^{34}$ Thus, the following research hypotheses are put forward:

H7a: Customer satisfaction positively affects Revisit intention.

H7b: Customer satisfaction positively affects the Word-ofmouth.

Concerning the relationship between WoM and revisit intention, scholars believe that the former is an antecedent of the latter. Recently, an empirical analysis of the United Arab Emirates' government healthcare system pointed out that WoM positively impacts inpatients' continuous use of the healthcare services provided by a given hospital. ${ }^{35}$ Similarly, the public healthcare industry in Turkey has also been proven to have a significant link between WoM and repurchase intentions. ${ }^{36}$ Meanwhile, while research on nursing satisfaction indicated that revisit intention is also negatively affected by negative $\mathrm{WoM} ;{ }^{37}$ therefore, the authors propose the following hypotheses:

H8: Word-of-mouth positively affects Revisit intention.

This literature illustrates the importance of service quality on CPV, customer satisfaction, and customer loyalty; however, specific research on private healthcare in
Vietnam is limited. With the qualitative findings and the literature gap, Figure 1 visualizes the conceptual model and research hypotheses.

\section{Methodology}

Research Design: Mixed-Method Approach

According to McKim, the combination of qualitative and quantitative research will allow researchers to generate insightful patterns on customer behaviors from in-depth interviews and verify these observations with rigorous analysis. $^{38}$ This combination will deliver both informationrich data and data-driven results for practical decisionmaking in organizations and businesses. Hence, this study employs a mixed-method approach to investigate the impact of service quality on revisiting behavior and the tendency to recommend inpatients in Vietnam's private healthcare industry.

Following this approach, researchers have designed the research into two phases. In Phase 1, the qualitative study conducted in-depth and open-ended interviews with inpatients. Between phases 1 and 2, the researcher used the collected data to develop four service quality dimensions and incorporated them with the literature to build a conceptual model for the quantitative phase. In Phase

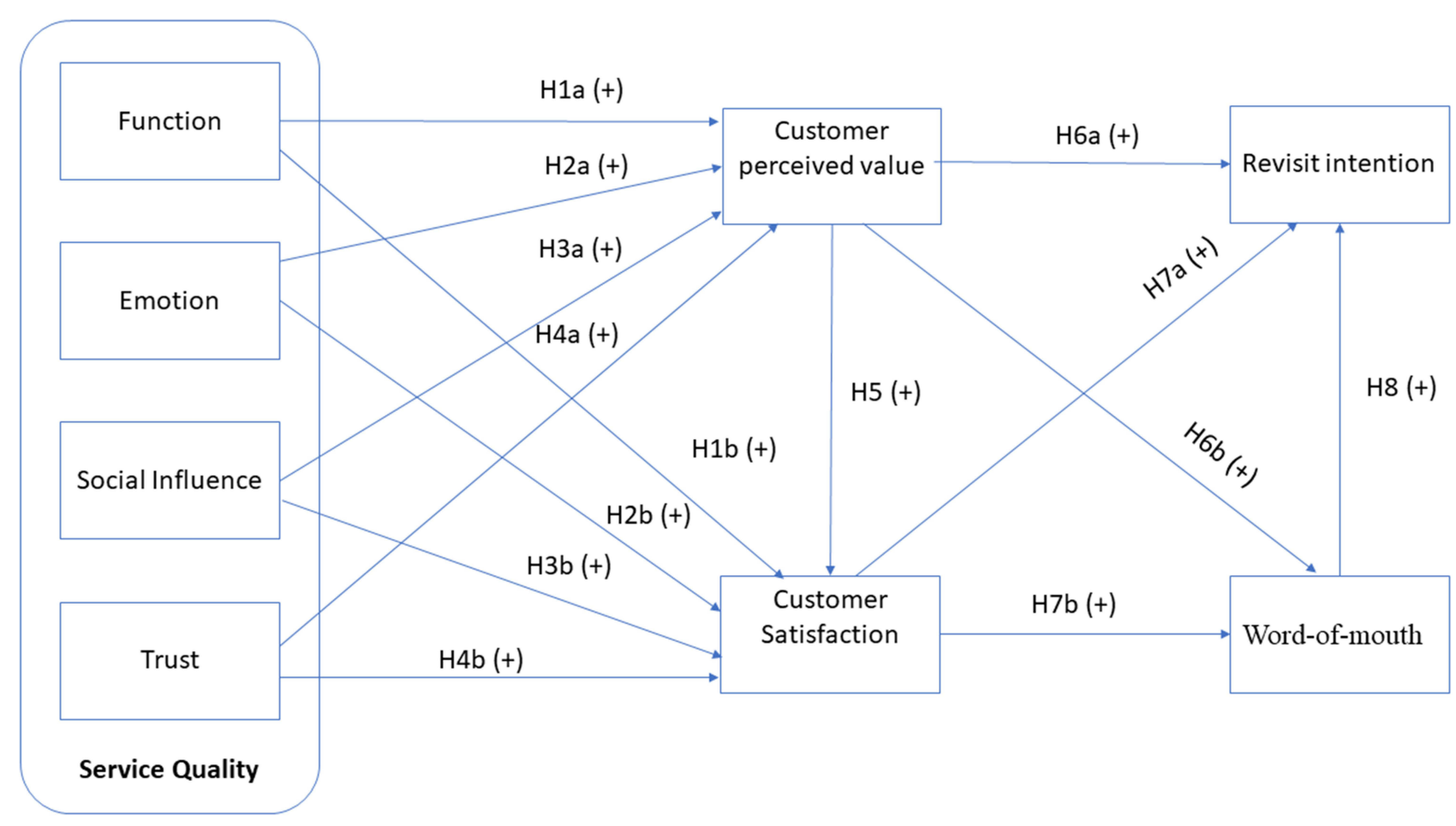

Figure I The conceptual model and research hypotheses. 
2, the research employed Covariance-based Structural Equation Modeling (CB-SEM) to analyze the relationship between each construct in the model, with the aim of determining how service quality in private healthcare can impact the revisit intention and WoM of inpatients.

\section{Phase I: Qualitative Study}

The qualitative phase explores the factors that influence service quality in the private healthcare context and how these factors might later impact revisit intention and WoM. To achieve this goal, the principal investigator conducted five in-depth interviews (Table 1) with private hospital inpatients via face-to-face or telephone interviews within Ho Chi Minh City, Vietnam. He has Ph.D. qualifications, works as a lecturer for MBA students, and has previous publications in qualitative studies. As the qualitative step only acts as a pivot to explore how inpatients perceive service quality, the researcher employed the convenience sampling method from a close professional network. However, the researcher had no formal relationship with the participants. While the researcher recruited 7 participants, two participants refused to schedule the interview because they had other personal commitments. The interviewed group included one male and four females with ages ranging from 20 to over 35 years. They experienced various medical problems, such as neurology, gastroenterology, and lungs, and they all recovered from their medical problems through interview sessions (Table 1). The diversity in participants' medical treatment backgrounds helps researchers identify and acknowledge the demand of inpatients across private healthcare contexts. Moreover, the researcher interviewed inpatients after hospital discharge to respect the participants' health and ensure that they had fully experienced the service and treatment process.

The purpose of using semi-structured questions is to cultivate targeted, rich and detailed information about the factors influencing individual decisions after using healthcare services. Each interview lasted 45 to 60 minutes via face-to-face or telephone interviews. Before the analysis, the research collected in-patient demographics and briefed them about the study's goals. The in-patient answers and opinions were recorded via audio and later coded into themes for analysis. After collecting information from the inpatients, the researchers then investigated the antecedents of service quality in the specific context of healthcare services in Vietnam, seeking answers for the Board of Directors at private hospitals to make decisions in the future. For this study, the researchers developed a series of 5 core questions to facilitate conversation and maintain consistency in data collection. This interview guide can also help researchers achieve the optimum interview time by systematically, comprehensively, and relevantly collecting responses. However, the interviewers sometimes adopted the interview framework when the participants came up with new insights or unexpected topics from the theories but relevant to their purchasing and WoM behavior. This research utilized the member checking method to ensure the quality of the response. By interacting again with the interviewees, the study can compare their data interpretation again with participants, ensuring credibility and validation of the analysis. ${ }^{39}$

This study employed content and thematic analyses to analyze the data. According to Braun and Clarke, in psychological and behavioral research, this method can "identifying, analyzing, and reporting patterns (themes) within the data" and use a "rigorous thematic approach to produce an insightful analysis that answers particular research questions." 40 Firstly, the recorded data will be transcribed and translated into English from Vietnamese via a forward and backtranslation approach to ensure clarity and consistency before and after translation. Two researchers who were fluent in both English and Vietnamese participated in this process. The researchers then coded the information and categorized them into groups of similar meaning patterns/themes. To ensure the quality of the analysis, the researcher organized a focus group meeting with medical experts. The practitioners comment on the findings concerning their medical practices and healthcare management, ensuring the credibility and applicability of the analysis.

Table I Demographic Characteristics of the Qualitative Samples

\begin{tabular}{|l|c|c|c|c|c|c|}
\hline No & Name & Age & Gender & Salary (VND) & Job & Treatment \\
\hline I & A & Over 35 & Female & 30.000 .000 & Business at home & Neurology \\
2 & B & Over 30 & Female & 15.000 .000 & Technician in laps & Lung \\
3 & C & 24 & Male & $10.000 .000-15.000 .000$ & Journalist & Not reported \\
4 & D & 23 & Female & 10.000 .000 & Staff at Hospital & Gastroenterology \\
5 & E & 23 & Female & 10.000 .000 & Student & General Medicine \\
\hline
\end{tabular}


Table 2 Demographic Characteristics of the Quantitative Samples

\begin{tabular}{|c|c|c|c|}
\hline \multicolumn{2}{|c|}{ Demographic Characteristics } & \multicolumn{2}{|c|}{ Sample's Specifics N=368 } \\
\hline & & \multirow{3}{*}{$\begin{array}{c}\text { Frequency } \\
188 \\
180\end{array}$} & \multirow{3}{*}{$\begin{array}{c}\text { Percentage (\%) } \\
51.1 \\
48.9\end{array}$} \\
\hline Gender & Male & & \\
\hline & Female & & \\
\hline \multirow[t]{4}{*}{ Age } & $0-25$ & 43 & 11.7 \\
\hline & $26-35$ & 89 & 24.2 \\
\hline & $36-50$ & 113 & 30.7 \\
\hline & $51-60$ & 123 & 33.4 \\
\hline \multirow[t]{4}{*}{ Educational Level } & High school and below & 88 & 23.9 \\
\hline & Vocational training & 78 & 21.2 \\
\hline & Associate & 99 & 26.9 \\
\hline & Bachelor's and higher & 103 & 28.0 \\
\hline \multirow[t]{4}{*}{ Income (VND) } & $0-10,000,000$ & 97 & 26.4 \\
\hline & $10,000,00 \mid-15,000,000$ & 108 & 29.3 \\
\hline & $|5,000,00|-30,000,000$ & 90 & 24.5 \\
\hline & Above $30,000,000$ & 73 & 19.8 \\
\hline \multirow[t]{6}{*}{ Job } & Student & 96 & 26.1 \\
\hline & Civic officer & 98 & 26.6 \\
\hline & Researcher-Educational activist & 55 & 14.9 \\
\hline & Blue-collar worker & 52 & 14.1 \\
\hline & Artist & 46 & 12.5 \\
\hline & Other & 21 & 5.7 \\
\hline
\end{tabular}

\section{Phase 2: Quantitative Study}

The quantitative phase helps to explore the relationship between all constructs in the proposed model (Figure 1). This phase starts with a consultation meeting between the authors and medical experts, and language experts. While the language experts translated the measurement scales from English to Vietnamese, the medical experts edited the translated scale and incorporated the qualitative data to build a questionnaire that fits the Vietnamese medical context. This medical-language expert session helped researchers develop a questionnaire with the consistency and clarity of dimensions and items. This questionnaire consists of two parts: (1) socio-demographic information (See Table 2) and (2) the scales for all measured constructs in the theoretical model. In part 2 of the questionnaire, the eight constructs were function, emotion, trust, social influence, $\mathrm{CPV}$, customer satisfaction, WoM, and revisit intention. The questionnaire consists of 33 items, measured on a seven-point Likert-type scale ranging from "strongly disagree" (1) to "strongly agree" (7). Table 3 provides a description of the constructs and their scales.

To test the model, the researchers developed a questionnaire to gather empirical data from a sample of
368 inpatients who used to stay at private hospitals in Ho Chi Minh City via snowball sampling from March to June 2020. Regarding the distribution of the questionnaire, the researchers utilized Google Survey and hardcopy to send and record the answers. A sample size of 368 qualified to testify the statistical significance, calculated as the number of free parameters in each model was multiplied by $10 .^{41}$ The sample had diverse backgrounds regarding gender, age, and education. Specifically, male respondents accounted for $51.1 \%$ of the responses while female respondents accounted for $48.9 \%$. The age distribution has a high representation of Millennials and generation X (aged 26 to 60), which accounted for $80 \%$ of the respondents. Regarding education, most respondents had at least an associate or bachelor's degree, and only $23.9 \%$ of respondents did not attend higher education. Regarding the occupation, $26.6 \%$ are civil servants, $26.1 \%$ are students, $14.9 \%$ are researchers and educators, $14.1 \%$ are unskilled labor, $12.5 \%$ work in entertainment, and $5.7 \%$ claim "others." A summary of this distribution is provided in Table 2.

After data collection, the researchers imported these raw materials into Excel for preliminary screening and data cleaning. To ensure the reliability and validity of the multi-item 
Table 3 Questionnaire Structure for Inpatients in the Quantitative Phase

\begin{tabular}{|c|c|c|c|}
\hline Dimension & Item & Code & References \\
\hline Trust & $\begin{array}{l}\text { This hospital has a good reputation } \\
\text { Staff at the hospital are honest and trustworthy } \\
\text { The staff of this hospital cares to solve the inpatients' problems } \\
\text { My health care provider offers me the highest quality in medical care } \\
\text { Hospital commitment is to meet in-patient needs and satisfaction }\end{array}$ & $\begin{array}{l}\text { TRUSTI } \\
\text { TRUST2 } \\
\text { TRUST3 } \\
\text { TRUST4 } \\
\text { TRUST5 }\end{array}$ & $\begin{array}{l}\text { Adopt from the } \\
\text { qualitative result }\end{array}$ \\
\hline Function & $\begin{array}{l}\text { Doctors fulfilled my expectation } \\
\text { Reception personnel fulfilled my expectation } \\
\text { The cleanliness of the hospital fulfilled my expectation } \\
\text { Working time at the hospital fulfilled my expectation } \\
\text { Diagnostic examination at the hospital fulfilled my expectation }\end{array}$ & $\begin{array}{l}\text { FUNTII } \\
\text { FUNTI2 } \\
\text { FUNTI3 } \\
\text { FUNTI4 } \\
\text { FUNTI5 }\end{array}$ & $\begin{array}{l}\text { Adopt from the } \\
\text { literature }{ }^{17 *}\end{array}$ \\
\hline Emotion & $\begin{array}{l}\text { Using services would make me feel/experience well after leaving } \\
\text { I believe the hospital strives to do the best for inpatients } \\
\text { I believe the hospital knows what kind of experience inpatients want }\end{array}$ & $\begin{array}{l}\text { EMOTII } \\
\text { EMOTI2 } \\
\text { EMOTI3 }\end{array}$ & $\begin{array}{l}\text { Adopt from the } \\
\text { literature }{ }^{20 * *}\end{array}$ \\
\hline Social influence & $\begin{array}{l}\text { I found out that other inpatients always leave me a good impression of the hospital's } \\
\text { services } \\
\text { The presence of other inpatients does not affect the hospital's ability to provide the } \\
\text { best service } \\
\text { The hospital understands that other inpatients influence my comment about their } \\
\text { services }\end{array}$ & $\begin{array}{l}\text { SOFLUI } \\
\text { SOFLU2 } \\
\text { SOFLU3 }\end{array}$ & $\begin{array}{l}\text { Adopt from the } \\
\text { qualitative result }\end{array}$ \\
\hline $\begin{array}{l}\text { Customer } \\
\text { perceived value }\end{array}$ & $\begin{array}{l}\text { The hospital provides high-quality services } \\
\text { My effort to get to this hospital was well-deserved } \\
\text { Overall, I was satisfied with this hospital fee } \\
\text { The hospital offers a reasonable price for its services } \\
\text { The hospital's services are worth the money spent } \\
\text { The hospital offered good value for my money }\end{array}$ & $\begin{array}{l}\text { PERVAI } \\
\text { PERVA2 } \\
\text { PERVA3 } \\
\text { PERVA4 } \\
\text { PERVA5 } \\
\text { PERVA6 }\end{array}$ & $\begin{array}{l}\text { Adopt from the } \\
\text { qualitative result }\end{array}$ \\
\hline $\begin{array}{l}\text { Customer } \\
\text { satisfaction }\end{array}$ & $\begin{array}{l}\text { I am satisfied with the health care provided } \\
\text { The hospital has met all our expectations } \\
\text { Compared with other hospitals, the level of satisfaction was high } \\
\text { Choosing this company has proven a wise decision } \\
\text { Overall, I am satisfied with this hospital }\end{array}$ & $\begin{array}{l}\text { SATISI } \\
\text { SATIS2 } \\
\text { SATIS3 } \\
\text { SATIS4 } \\
\text { SATIS5 }\end{array}$ & $\begin{array}{l}\text { Adopt from the } \\
\text { literature }{ }^{42 * * *}\end{array}$ \\
\hline Revisit intention & $\begin{array}{l}\text { I consider the organization the first choice among all healthcare service organizations } \\
\text { in the area. } \\
\text { We will continue to use the existing products and services and purchase additional } \\
\text { product lines offered by this hospital } \\
\text { We will keep in touch with employees of the company for future coverage }\end{array}$ & $\begin{array}{l}\text { REVISII } \\
\text { REVISI2 } \\
\text { REVISI3 }\end{array}$ & $\begin{array}{l}\text { Adopt from the } \\
\text { literature }{ }^{43 * * *}\end{array}$ \\
\hline Word of mouth & $\begin{array}{l}\text { We will introduce this hospital to others } \\
\text { I seldom do more than mention the name of this service organization to others } \\
\text { We will tell people more about this company than any other insurance company } \\
\text { We will not miss the opportunity to tell others about this hospital } \\
\text { We will say good things about this hospital } \\
\text { We are proud to tell others about the products and services offered by this company }\end{array}$ & $\begin{array}{l}\text { WOROFMI } \\
\text { WOROFM2 } \\
\text { WOROFM3 } \\
\text { WOROFM4 } \\
\text { WOROFM5 } \\
\text { WOROFM6 }\end{array}$ & $\begin{array}{l}\text { Adopt from the } \\
\text { literature }{ }^{43 * * *}\end{array}$ \\
\hline
\end{tabular}

Notes: *Adapted from: Budrevičiūtè A, Kalèdienė R, Bagdonienė L, Paukštaitienė R, Valius L. Perceptions of social, emotional, and functional values in patients with type 2 diabetes mellitus and their satisfaction with primary health care services. Primary Health Care Research \& Development. 2019;20:el22. ${ }^{17}$ () The Author(s) 2019. Creative Commons Attribution licence (http://creativecommons.org/licenses/by/4.0/). **Reprinted from: Sweeney JC, Soutar GN. Consumer perceived value: The development of a multiple item scale. Journal of Retailing. 2001;77(2):203-220. ${ }^{20}$ Copyright 200I, with permission from Elsevier. ****Reprinted from: Ndubisi NO. Mindfulness, reliability, pre-emptive conflict handling, customer orientation and outcomes in Malaysia's healthcare sector. Journal of Business Research. 2012;65(4):537-546. ${ }^{42}$ Copyright 2012, with permission from Elsevier. *****Adapted from: Nguyen N. Service quality, customer perceived value and repurchase intention in B2B professional service context - the case of general insurance sector in Vietnam [thesis]. Ho Chi Minh City: Vietnam National University; 2019. Available from: https://hcmiu.edu.vn/wp-content/uploads/2020/08/PhD-DISSERTATION-Nguyen-Xuan-Nhi-after-defensecompressed.pdf. Accessed October 8, 2021. ${ }^{43}$ 
scales, researchers used the SPSS 21 software to conduct the Scale reliability test (Cronbach's Alpha) for internal consistency and Average variance extracted (AVE) and Composite Reliability (CR) for validity tests. Finally, The AMOS 22 software will perform Confirmatory factor analysis (CFA) and CB-SEM.

\section{Results \\ Qualitative Findings Service Quality's Dimension Exploration}

After interviewing 5 participants, the preliminary qualitative phase generated content-rich data about the antecedents of service quality and customer-decision making factors in the specific context of healthcare services in Vietnam. The data analysis helped develop four dimensions of service quality: emotion, function, social influence, and trust. Each developed construct shares many similar themes among interviewees, providing some first insights about the customers' expectations of the service quality of private healthcare in Vietnam and what factors determine their customer loyalty (Figure 2). As the inpatient sample in this phase is relatively small, their answers only explore potential healthcare quality topics and recommendations for private healthcare rather than representing the demand and opinion of most Vietnamese citizens.

First, inpatients commonly suffer pain or worries when they come to a private hospital; hence, providing better service is an effective way to share and relieve their pain. However, emotion is less content-wise than other constructs during the preliminary phase; hence, they do not have distinctive themes. However, recurring keywords were comfortable and supportive. These keywords can come from positive emotional contexts, such as "creating comfortable environments between inpatients and caregivers." They can also derive from negative emotional contexts, including that the customer service team is not welcoming and approachable to initiate a refund process. According to the inpatients, post-treatment caring services or service feedback collection can also raise positive emotions and develop emotional bonds between inpatients and treatment centers.

Second, according to the customers, the function concentrates on the timeliness and sanitation of the facilities. The expected functions are the cleanliness of the room and equipment or how fast and convenient the medical test can be delivered to inpatients. In-patients also expect private hospitals to have more modern equipment and more complex or specialized tests than public medical institutions. In-patients also mention the need for specialized customer care services, which are rare and undeveloped in the public sphere. For example, one said: "Private hospitals have medical tests with an acceptable price that are not available at public ones". These demands are recurring across interviews, showing examples of healthcare functions that private firms can utilize to develop a competitive advantage over public hospitals.

Third, the inpatients acknowledge the role of social branding and medical institutions' contributions to society and the digital space. The participants highly praised the pro bono services of private institutions in the digital space, such as hosting medical webinars or providing free medical advice. These events help the patient perceive doctors' expertise and promote virtual engagement between patients and doctors. The patient's appreciation from communicating with medical experts during the treatment process resulted in satisfaction and long-term loyalties. Moreover, if the participant perceives that a private institution has high quality via digital and social activities, they will be more likely to recommend their friends and relatives. All respondents confirmed that their decisions to acquire services from private hospitals came from close friends and families who were happy with the services and treatment results. The reputation of a private hospital on social media and service review websites also influences the decision to use and re-use healthcare services. In short, the interviews show that social-digital activities can influence inpatients' perceptions of quality before, during, and after the treatment process. They also highlight the importance of women in customer loyalty development and client acquisitions.

Finally, the elements of trust were mentioned many times by interviewees. Most inpatients prefer old and experienced doctors rather than young doctors, and even the youth might receive better education and training. All respondents agreed that the employees (doctors and nurses) were the primary source of trust in the private healthcare context in Vietnam. They associate reliable medical staff as attentive and knowledgeable people who are always available and provide easy-to-follow guidance from the examination stage to receive the results. Surprisingly, only a few respondents mentioned trust in gaining cutting-edge types of equipment. This preliminary analysis might indicate that the human element in treatment brings more trust to customers than the modern and 


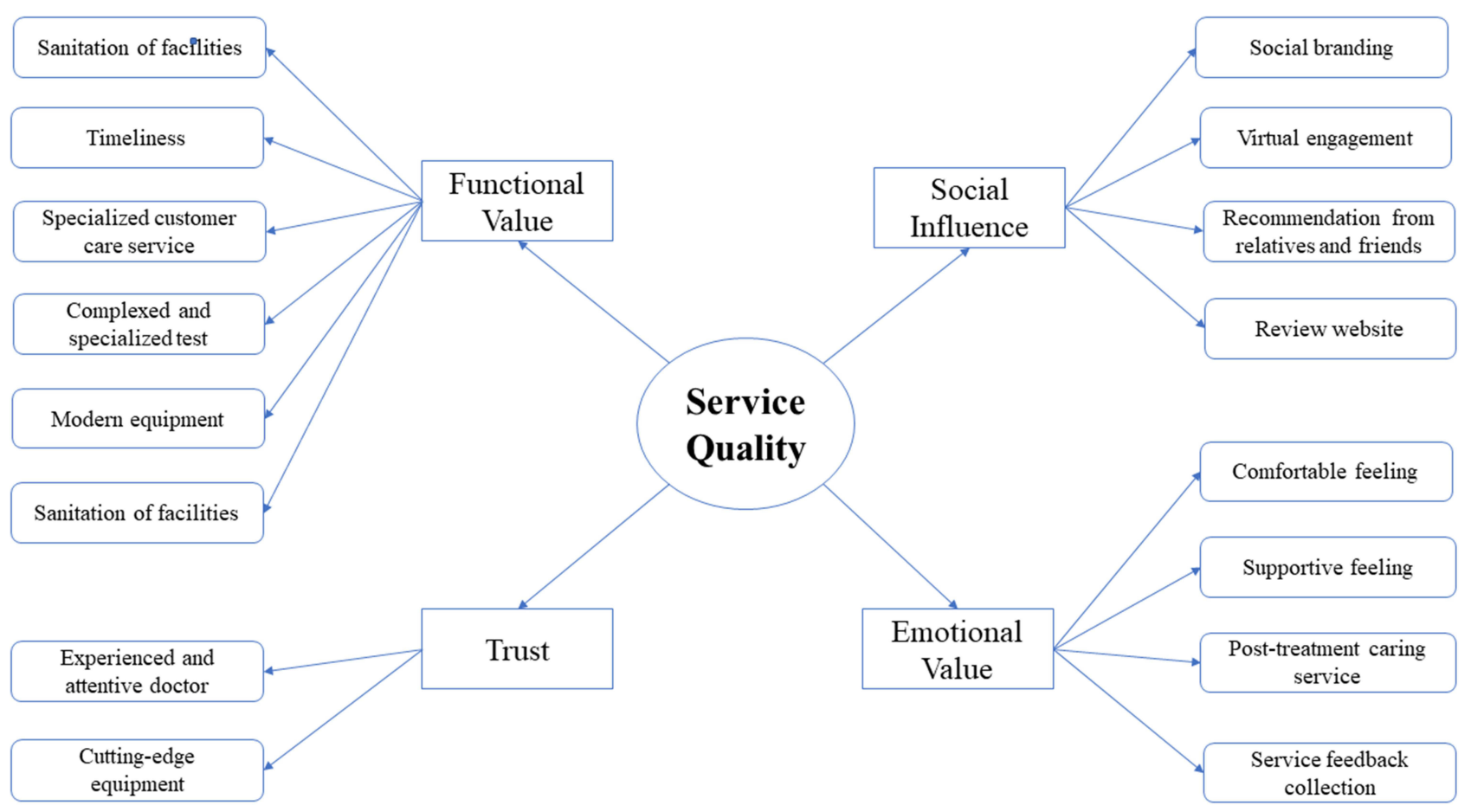

Figure 2 Qualitative results: the in-patients' cognitive map.

potential effectiveness of technologies for Vietnamese inpatients.

According to the interview data, all five patients agreed on three priority improvements: (1) Training a team of highly knowledgeable medical experts with strong personal skills, namely empathy and communication; (2) shifting the administrative procedures to save time; and (3) building a solid social media presence and pro bono and e-service to justify their expertise. Each suggestion addresses multiple dimensions of service quality. For instance, personal skills and medical training programs will benefit the emotion and trust dimension, while social media presence and e-service contribute to the function and social influence dimensions. Although the scope of this research does not conduct a costbenefit analysis for these suggestions, their applicability will be discussed again in the Discussion Section.

\section{Quantitative Findings} Internal Reliability and Validity Results

Internal reliability was calculated using the Cronbach's Alpha coefficient test at a benchmark of 0.7 . For the validity test, the value of 0.5 for AVE and 0.7 for CR were the standard. ${ }^{43}$ All measured constructs met the criteria for internal reliability and validity (Table 4). Subsequently, Exploratory Factor Analysis (EFA) and Confirmatory Factor Analysis (CFA) were conducted. In this research, the EFA criterion is 0.5 , which is reliable according to a previous study. ${ }^{44}$ After removing three items that could not pass the 0.5 benchmarks, namely PERVA3, FUNTI2, and TRUST5, during EFA analysis, 33 items continued to the CFA analysis. Appendix 1 summarizes the results of the EFA analysis and its benchmarks, and Appendix 2 shows the results of the last factor rotation matrix. Through CFA analysis, the researchers observed that the values of $\mathrm{CMIN} / \mathrm{DF}=$ 2.515, TLI (0.927), and CFI $(0.936)>0.9$. The GFI index reached $0.839(>0.8)$, RMSEA index reached $0.064(<0.08)$, and sig test value of model 0.000 $(<0.05){ }^{44}$ hence, the analytical data were compatible

Table 4 Constructs Reliability and Validity: Cronbach's Alpha, Average Variance Extracted (AVE) and Composite Reliability (CR)

\begin{tabular}{|l|c|c|c|}
\hline Factor & Cronbach's Alpha & AVE & CR \\
\hline Trust & 0.869 & 0.911 & 0.720 \\
Function & 0.824 & 0.892 & 0.675 \\
Emotion & 0.872 & 0.873 & 0.836 \\
Social influence & 0.847 & 0.850 & 0.655 \\
Customer perceived value & 0.906 & 0.946 & 0.777 \\
Customer satisfaction & 0.914 & 0.916 & 0.687 \\
Revisit intention & 0.906 & 0.910 & 0.772 \\
Word of Mouth & 0.957 & 0.955 & 0.780 \\
\hline
\end{tabular}


Table 5 Status of Research Hypotheses After Performing SEM Analysis

\begin{tabular}{|c|c|c|c|c|c|}
\hline Hypothesis & Latent & Estimate & S.E & P-value & Result \\
\hline HIa & Trust -> CPV & 0.205 & 0.073 & 0.005 & Supported \\
\hline $\mathbf{H} \mathbf{2 a}$ & Function $->$ CPV & 0.138 & 0.070 & 0.048 & Supported \\
\hline H3a & Emotion -> CPV & 0.087 & 0.048 & 0.069 & Not Supported \\
\hline $\mathrm{H} 4 \mathbf{a}$ & Social influence -> CPV & 0.276 & 0.082 & $* * *$ & Supported \\
\hline HIb & Trust -> Customer satisfaction & 0.217 & 0.068 & 0.001 & Supported \\
\hline $\mathbf{H} 2 \mathrm{~b}$ & Function -> Customer satisfaction & 0.048 & 0.064 & 0.450 & Not Supported \\
\hline H3b & Emotion -> Customer satisfaction & 0.118 & 0.044 & 0.008 & Supported \\
\hline H4b & Social influence -> Customer satisfaction & 0.324 & 0.078 & $* * *$ & Supported \\
\hline H5 & CPV -> Customer satisfaction & 0.205 & 0.073 & 0.124 & Not Supported \\
\hline H6a & CPV -> Revisit intention & 0.081 & 0.052 & $* * *$ & Supported \\
\hline H6b & CPV -> WoM & 0.253 & 0.057 & $* * *$ & Supported \\
\hline H7a & Customer satisfaction -> Revisit intention & 0.305 & 0.066 & $* * *$ & Supported \\
\hline H7b & Customer satisfaction -> WoM & 0.297 & 0.060 & $* * *$ & Supported \\
\hline H8 & WoM -> Revisit intention & 0.247 & 0.061 & $* * *$ & Supported \\
\hline
\end{tabular}

Note: $* * * 0.000$

with the hypothesis model at $95 \%$ confidence. Finally, all square roots of AVEs are higher than their respective interconstruct correlations; hence, the scale achieves a discriminant value with the current data.

\section{Structural Equation Models: A Multi-Group Analysis}

After performing Exploratory Factor Analysis (EFA) and Confirmatory Factor Analysis (CFA), the researchers performed a linear structural model (SEM) analysis to test the research hypotheses and measure the impact of factors on each other. Based on the results of the SEM analysis, the conformity assessment results of the model were satisfactory: $\mathrm{CMIN} / \mathrm{df}=2.667(<3), \mathrm{TLI}=0.920$ and $\mathrm{CFI}=0.928$ $(>0.9)$, GFI $=0.830>0.8$, RMSEA $=0.067(<0.08)$, P-value test value relevance $=0.00(<0.05) .{ }^{44}$ Hence, at $95 \%$ confidence, the data are suitable for the SEM analysis model. The results are presented in Table 5. Before concluding the investigation for the hypotheses, Bootstrapping, which deploys random sampling with replacement, is used to save money and resources. The analysis indicates that the average estimated coefficients bear little difference from conventional estimation methods. In addition, there is little chance for the estimated errors between the two approaches to occur; hence, the model's estimated coefficients are a reliable source of safe results.

At $95 \%$ confidence, the results support 11 hypotheses and reject the three hypotheses (Table 5). To summarize, emotion did not show a significant relationship with the CPV (H3a). In addition, neither function nor CPV significantly affected customer satisfaction ( $\mathrm{H} 2 \mathrm{~b}$ and $\mathrm{H} 5$ ).
Among the four service quality dimensions, the impact of social influence on CPV $(0.276, \mathrm{P}=0.000)$ was the most significant, while that of function $(0.138, \mathrm{P}=0.048)$ was the least. The results also show that social influence has the most significant effect on customer satisfaction $(0.324, \mathrm{P}=0.000)$ while emotion $(0.118, \mathrm{P}=0.008)$ had the most negligible effect on this construct. Regarding customer loyalty, both $\mathrm{CPV}$ and customer satisfaction exercises positively influenced WoM and revisit intention (Table 5). Finally, the findings also show that WoM positively affects revisit intentions.

\section{Discussion}

This study illustrates the impact of service quality, CPV, and customer satisfaction on customer loyalty. There are some insightful observations after the mixed-method analysis. In terms of contribution to empirical knowledge, this research confirms that the relationships, questioned by a recent study, that total quality management in the public healthcare context has the same effects on perceived value, customer satisfaction, and customer loyalty as in the private ones. ${ }^{7}$ More specifically, patient satisfaction has a statistically significant impact on loyalty, specifically revisit intention $(0.305 ; \mathrm{p}=0.000)$ and WoM $(0.247 ; \mathrm{p}=$ $0.000)$. Most of the service quality dimensions also had a statistically significant impact on the CPV and CS (Table 5). Likewise, this research assists in closing the gap in research on perceived crowding in Vietnamese public institutions. In that article, the authors pointed out that patients of public institutions considered hospitals' service quality higher when hospitals are crowded, but 
suspected patients of private institutions would be unsatisfied with crowded hospitals. ${ }^{8}$ This paper successfully explores their suspicions through in-depth interviews.

However, one unconventional finding is that the $\mathrm{CPV}$ does not significantly impact customer satisfaction $(0.205 ; \mathrm{P}=$ 0.073 ) in the Vietnamese private healthcare context. This finding contradicts the results of a recent Vietnamese study and the literature when they tested this relationship in the healthcare context beyond Vietnam. ${ }^{7,26,27}$ The researcher hypothesizes that the reasons might be due to two reasons. First, the sample size of the quantitative results might not be large or diverse enough to represent the entire population of Vietnam. Second, many respondents received treatment at the hospitals. Since their health is at risk, they might not feel satisfied yet because this feeling typically occurs only after the treatment process. Regardless, this finding raises new questions for future research to identify the answers and bridge the contrast of the findings.

Second, during the in-depth interview phase, trust, emotion, function, and social influence were illustrated as potential CPV and customer satisfaction predictors. The quantitative results confirm that trust and social influence have considerable impacts on both CPV and customer satisfaction (See Table 5). However, the function did not significantly influence customer satisfaction $(0.048 ; \mathrm{P}=0.450)$. This result supports a recent systematic review, revealing that outcome measures concentrating on improving communication and interaction between patients and doctors brought more significant results than those concentrating on changing processes. ${ }^{45}$ Therefore, although the qualitative phase emphasizes improving medical procedures and training conscientious medical staff, medical practitioners should prioritize training medical staff over procedures in a limited time and financial budget.

Moreover, quantitative data showed that emotional elements did not play an essential role in promoting CPV (0.087; $\mathrm{P}=0.069)$. However, this dimension positively drives customer satisfaction, which eventually leads to positive WoM and revisit intentions. This observation might suggest that investing in a pre-treatment emotionally driven campaign might not be a practical option as customers do not perceive the service quality with these elements on the first purchase. Private healthcare services should nurture a sense of care and inclusion during the treatment process and provide posttreatment customer care. However, these suggestions should be considered with caution because this finding that emotion does not impact the CPV contrasts with previous studies in healthcare and non-healthcare contexts beyond the Vietnamese context. $^{17,21}$
Third, this study brings about variable novelty. In a recent paper about Vietnam, 7 the authors mentioned total quality management. However, they do not explain the dimensions of total quality management contextualized in the context of Vietnam. This research used an in-depth interview approach to propose four dimensions of service quality (emotion, function, trust, and social influence). The three first dimensions are similar to the suggestions of the SERVAL model; however, social influence is a novel variable that has gained little mention according to a recent systematic review. Social influence is derived from the Unified Theory of Acceptance and Use of Technology (UTUAT), a frequently used research on adoption behavior that has not been used to explore its' impact on CPV and customer satisfaction in the healthcare context. ${ }^{46}$ Previous research has illustrated the positive impact of social influences on customer satisfaction, customer loyalty, and customer lifetime value in non-medical industries, such as retail banking and online life insurance. ${ }^{47,48}$ Moreover, previous research has studied the direct implications of social influence on customer loyalty; however, their indirect influence on customer satisfaction is limited. ${ }^{24}$ Therefore, this research confirms the positive effects of social influence on customer satisfaction in the context of private healthcare.

Finally, the original SERVAL model and previous studies underestimated the value of digital service. ${ }^{48}$ However, in our qualitative phase, interviewees mentioned e-service or its impacts on satisfaction and perceived value multiple times. Although not directly testify to the influence of e-service and patients' feedback on digital space, existing literature has also found positive outcomes of digital engagement between patients and doctors. ${ }^{48,49}$ Direct comments and feedback on the quality of healthcare services via social media promote transparency of service quality and motivate practitioners to improve their skills and services. ${ }^{50}$ Interaction strategies with patients on social media can also provide emotional support, esteem support, social comparison, and faster booking. The benefits of social influence are in agreement with service quality criteria. ${ }^{51}$ Therefore, investment in e-service or social media interaction may increase customers' loyalty, perceived value, and satisfaction in the Vietnamese private healthcare system. Specially applied in the Covid-19 pandemic, healthcare services can reach out to an increasing number of customers.

The qualitative result also shows the crucial roles of recommendation between friends and family members on the participation and revisiting behaviors of potential inpatients. Moreover, among service quality dimensions, social influence had the most substantial impact on $\mathrm{CPV}(0.276, \mathrm{P}=0.082)$ and 
customer satisfaction $(0.048, \mathrm{P}=0.064)$ in the quantitative result. Positive recommendations from inpatients also improve in-patient revisit intentions, as supported by previous research on healthcare. ${ }^{37-52}$ This result might suggest that in the case of financial resource constraints, managers should prioritize social influence to enhance CPV and customer satisfaction, attracting them to purchase private healthcare treatment in the first place. For instance, private hospitals should concentrate on loyalty programs, such as discounts for family members or social media marketing.

\section{Conclusion, Limitation, and Future Research}

The application of mix-methods generates insightful and tailored content-rich data from customers and tests these relationships with large and statistically significant sample sizes. First, the qualitative phase develops a framework to improve service quality for private healthcare institutions in Vietnam, addressing the gaps proposed by previous scholars in Vietnam. Second, Structural Equation Modeling (SEM) tests these relationships, and the results show that the data largely support the model. This indicates that service quality positively influences $\mathrm{CPV}$ and customer satisfaction, which also significantly impacts customer loyalty.

On the theoretical implication, this research makes novel contributions to the existing literature on service quality and customer loyalty in the healthcare context. First, it explores the impact of service quality on $\mathrm{CPV}$, customer satisfaction, and customer loyalty in the context of Vietnam's private healthcare sector, which has long been under-researched but has significant economic and commercial value. Unlike previous literature, this study interviewed hospital inpatients to obtain service quality indicators and then combined them with CPV and customer satisfaction results to build the conceptual model. In the qualitative phase, the research also provides the first step in understanding the roles of online feedback websites and e-services on the constructs of social influence and how these services may impact WoM, and revisit intention in the private healthcare context.

On the managerial implication, the research suggests that improving service quality can help private hospitals attract and retain more inpatients. Practical suggestions from customer viewpoints may also provide a stepping stone for more effective investment in the private health business. For instance, private hospitals can improve customer loyalty by developing attentive medical staff and considering e-service or online pro bono services as trust and social influence significantly impact CPV and CS. Private hospital managers should pay attention to social media and post-treatment services to attract new customers via WoM and increase the chance of being revisited by inpatients. Future research can use pre-post tests and costbenefit analyses to test the effectiveness of different recommendations from this study to provide more practical advice to private healthcare businesses in Vietnam.

This study had some limitations. First, researchers carried out this research before the COVID-19 pandemic. Thus it cannot include the effects of the current crisis on the research results. Therefore, future research can repeat the analysis to explore how and why the pandemic has affected the promotion of private healthcare. Second, the constructs of this research are limited to functional value, emotional value, social value, and trust. However, future research may use other constructs such as ten constructs (reliability, responsiveness, competence, access, courtesy, communication, credibility, security, understanding/knowing the customer, tangibles) proposed by Parasuraman to obtain a comprehensive perspective. 38 Third, our research findings indicate that the effects of CPV on customer satisfaction are not significant, which contradicts many results in the literature. Hence, it is suggested that scholars conduct more qualitative research with this scale or increase the sample size to bring about a consistent result. Finally, the sample in the study only includes residents in Ho Chi Minh City, Vietnam, and there are no people over 60 years old. The data might weigh the Millennials and Generation Z's opinions higher than the older generations, such as the Baby Boomer and Gen X generations. The age distribution might still be valid for the study because the Millennials and Generation $\mathrm{Z}$ are the most likely and financially capable of becoming private healthcare customers. However, this sample cannot statistically represent the opinions of all Vietnamese citizens regarding the relationship between service quality and customer loyalty. Therefore, it fails to reflect the pattern of the whole nation. Future research needs a more comprehensive and inclusive sample.

\section{List of Abbreviations}

CPV, Customer perceived value; WoM, Word-of-mouth.

\section{Data Sharing Statement}

The datasets used and/or analyzed during the current study are available from the corresponding author upon reasonable request. 


\section{Ethics Approval and Consent to Participate}

The study was conducted in accordance with the Declaration of Helsinki and the Vietnamese regulations. Under Circular No.4/ TT-BYT, the scope of IRB covers only Biomed studies (defined in the Circular at Article 15, Section a: (1) clinical trials of drugs, (2) equipment, and (3) other products that have not yet been licensed for circulation in Vietnam). An ethics committee review was not required because the study was conducted for service evaluation. The institutional review board of Nguyen Tat Thanh University waived the IBR for this research because the recorded information could not readily identify the subject. Any disclosure of responses outside the research could not reasonably place the subject at risk. All participants provided written consent to participate in the study through acceptance of the invitation. Participants under 16 years of age provided written informed consent from their parents or guardians.

\section{Consent for Publication}

This manuscript does not contain any identifiable data.

\section{Acknowledgments}

The authors would like to acknowledge and thank all the participants in this study. We also express our gratitude to the medical and language experts who provided us with advice on questionnaire development and language editing.

\section{Author Contributions}

All authors made a significant contribution to the work reported, whether that is in the conception, study design, execution, acquisition of data, analysis and interpretation, or in all these areas; took part in drafting, revising or critically reviewing the article; gave final approval of the version to be published; have agreed on the journal to which the article has been submitted; and agree to be accountable for all aspects of the work.

\section{Funding}

There was no funding for this research project.

\section{Disclosure}

The authors declare that they have no conflicts of interest for this work. The views expressed are those of the authors and do not represent the views of any organization or agency to which they are affiliated.

\section{References}

1. Nguyen MP, Wilson A. How could private healthcare better contribute to healthcare coverage in Vietnam? Int J Health Policy Manage. 2017;6(6):305-308. doi:10.15171/ijhpm.2017.05

2. Willems J, Ingerfurth S. The quality perception gap between employees and patients in hospitals. Health Care Manage Rev. 2018;43 (2):157-167. doi:10.1097/HMR.0000000000000137

3. Hilligoss B, Tanenbaum SJ, Paul MH, Ferrari RM, Song PH. What makes health services usable?: insights from a qualitative study of caregivers of children with disabilities. Health Care Manage Rev. 2021;46(2):111-122. doi:10.1097/HMR.0000000000000249

4. Fatima I, Humayun A, Iqbal U, Shafiq M. Dimensions of service quality in healthcare: a systematic review of literature. Int $J$ Qual Health Care. 2019;31(1):11-29. doi:10.1093/intqhe/mzy125

5. Bucatariu L, George BP. Patient perception and choice factors related to international hospitals: a study in ho chi minh city, Vietnam. J Health Med Inf. 2017;08(03). doi:10.4172/2157-7420.1000277

6. Tat S, Barr D. Healthcare in the New Vietnam: comparing patients' satisfaction with outpatient care in a traditional neighborhood clinic and a new, western-style clinic in Ho Chi Minh City. Soc Sci Med. 2006;62(5):1229-1236. doi:10.1016/j.socscimed.2005.07.015

7. Nguyen TLH, Nagase K. Patient satisfaction and loyalty to the healthcare organization. IJPHM. 2021;ahead-of-print. doi:10.1108/ IJPHM-02-2020-0011.

8. Sawang S, Chou CY, Truong-Dinh BQ. The perception of crowding, quality and well-being: a study of Vietnamese public health services. JHOM. 2019;33(4):460-477. doi:10.1108/JHOM-08-2018-0233

9. Parasuraman A, Zeithaml VA, Berry LL. A conceptual model of service quality and its implications for future research. $J$ Mark. 1985;49(4):41-50. doi:10.1177/002224298504900403

10. Zarei E, Arab M, Mahmoud Ghazi Tabatabaei S, Rashidian A, Rahimi Forushani A, Khabiri R. Understanding patients' behavioral intentions: evidence from Iran's private hospitals industry. $J$ Health Organ Manage. 2014;28(6):795-810. doi:10.1108/JHOM-11-20120218

11. Zeithaml VA. Consumer perceptions of price, quality, and value: a means-end model and synthesis of evidence. J Mark. 1988;52(3):2. doi: $10.2307 / 1251446$

12. Jen W, Tu R, Lu T. Managing passenger behavioral intention: an integrated framework for service quality, satisfaction, perceived value, and switching barriers. Transportation. 2011;38(2):321-342. doi:10.1007/s11116-010-9306-9

13. Oliver RL. Whence consumer loyalty? J Mark. 1999;63 (4_suppl1):33-44. doi:10.1177/00222429990634s105

14. Parasuraman A, Zeithaml VA, Berry L. SERVQUAL: a multiple-item scale for measuring consumer perceptions of service quality. $J$ Retailing. 1988;64(1):12-40.

15. Park S, Kim H-K, Choi M, Lee M, Kielbassa AM. Factors affecting revisit intention for medical services at dental clinics. PLoS One. 2021;16(5):e0250546. doi:10.1371/journal.pone.0250546

16. Ward KF, Rolland E, Patterson RA. Improving outpatient health care quality: understanding the quality dimensions. Health Care Manage Rev. 2005;30(4):361-371. doi:10.1097/00004010-200510000-00010

17. Budrevičiūtè A, Kalèdienè R, Bagdonienè L, Paukštaitienè R, Valius L. Perceptions of social, emotional, and functional values in patients with type 2 diabetes mellitus and their satisfaction with primary health care services. Prim Health Care Res Dev. 2019;20: e122. doi: $10.1017 / \mathrm{S} 1463423619000471$

18. Zainuddin N, Russell-Bennett R, Previte J. The value of health and wellbeing: an empirical model of value creation in social marketing. Eur J Mark. 2013;47(9):1504-1524. doi:10.1108/EJM-10-2011-0564

19. Alotaibi M, Alazemi T, Alazemi F, Bakir Y. Patient satisfaction with primary health-care services in Kuwait: patient satisfaction with primary care. Int J Nurs Pract. 2015;21(3):249-257. doi:10.1111/ ijn. 12257 
20. Sweeney JC, Soutar GN. Consumer perceived value: the development of a multiple item scale. J Retailing. 2001;77(2):203-220. doi:10.1016/S0022-4359(01)00041-0

21. Ahn J, Kwon J. Green hotel brands in Malaysia: perceived value, cost, anticipated emotion, and revisit intention. Current Issues Tourism. 2020;23(12):1559-1574. doi:10.1080/13683500.2019.1646715

22. Svotwa TD, Roberts-Lombard M, Jaiyeoba O. Black Friday rituals, customer perceived value and loyalty among young adult customers in South Africa: a stimulus-organism-response perspective. Cogent Bus Manage. 2020;7(1):1793523. doi:10.1080/23311975.2020.1793523

23. Zarei E, Daneshkohan A, Pouragha B, Marzban S, Arab M. An empirical study of the impact of service quality on patient satisfaction in private hospitals, Iran. Glob J Health Sci. 2014;7(1):p1. doi: $10.5539 /$ gjhs.v7n1p1

24. Viswanathan P, Singh AB, Gupta G. The role of social influence and e-service quality in impacting loyalty for online life insurance: a SEM-based study. Int J Bus Excellence. 2020;20(3):322. doi:10.1504/IJBEX.2020.106370

25. Smith AE, Swinehart KD. Integrated systems design for customer focused health care performance measurement: a strategic service unit approach. Int J Health Care Qual Assur. 2001;14(1):21-29. doi:10.1108/09526860110366232

26. Abdel Fattah FAM, Dahleez KA, Darwazeh RN, Al Alawi AMM. Influence of service quality on consumer loyalty: a mediation analysis of health insurance. TQM J. 2021. doi:10.1108/TQM-09-2020-0219

27. Jaleel AA, Yajid MSA, Khatibi A, Azam SMF. Assessing the interrelationships between customer satisfaction, perceived value and behavioral intention among Maldivians seeking medical care within medical tourism services: empirical evidence from the Maldives. Manage Sci Letters. 2021;1845-1854. doi:10.5267/j.msl.2021.1.019

28. Azimi H. Ranking the effect of services marketing mix elements on the loyalty of customers by using Topsis method (Case study: city bank branches in Tehran). Innovative Marketing. 2017;13(2):41-46. doi:10.21511/im.13(2).2017.04

29. Yim CK, Tse DK, Chan KW. Strengthening customer loyalty through intimacy and passion: roles of customer-firm affection and customerstaff relationships in services. J Marketing Res. 2008;45(6):741-756. doi:10.1509/jmkr.45.6.741

30. Caruana A, Fenech N. The effect of perceived value and overall satisfaction on loyalty: a study among dental patients. $J$ Med Marketing. 2005;5(3):245-255. doi:10.1057/palgrave.jmm.5040236

31. Chahal H, Kumari N. Consumer perceived value and consumer loyalty in the healthcare sector. $J$ Relat Marketing. 2011;10(2):88-112. doi:10.1080/15332667.2011.577729

32. Özer L, Başgöze P, Karahan A. The association between perceived value and patient loyalty in public university hospitals in Turkey. Total Qual Manage Bus Excellence. 2017;28(7-8):782-800. doi:10.1080/14783363.2015.1124723

33. Meesala A, Paul J. Service quality, consumer satisfaction and loyalty in hospitals: thinking for the future. $J$ Retailing Consum Serv. 2018;40:261-269. doi:10.1016/j.jretconser.2016.10.011

34. Fatima T, Malik SA, Shabbir A. Hospital healthcare service quality, patient satisfaction and loyalty: an investigation in context of private healthcare systems. Int $J$ Qual Reliab Manage. 2018;35 (6):1195-1214. doi:10.1108/IJQRM-02-2017-0031

35. Dayan M, Al Kuwaiti IA, Husain Z, Ng PY, Dayan A. Factors influencing patient loyalty to outpatient medical services: an empirical analysis of the UAE's government healthcare system. Int J Qual Reliab Manage. 2021; ahead-of-print. doi:10.1108/IJQRM-11-2020-0373.
36. Kitapci O, Akdogan C, Dortyol İT. The impact of service quality dimensions on patient satisfaction, repurchase intentions and word-ofmouth communication in the public healthcare industry. Procedia - Soc Behav Sci. 2014;148:161-169. doi:10.1016/j.sbspro.2014.07.030

37. Heo EJ, Sung MS. Effects of nurses' effort to solve complaints on nursing satisfaction, negative word-of-mouth and revisit intention. Asia Life Sci. 2018;15(2):765.

38. McKim CA. The value of mixed methods research: a mixed methods study. J Mix Methods Res. 2017;11(2):202-222. doi:10.1177/ 1558689815607096

39. Matthes J, Davis CS, Potter RF, eds. The International Encyclopedia of Communication Research Methods. 1st ed. Wiley; 2017. doi:10.1002/9781118901731

40. Braun V, Clarke V. Using thematic analysis in psychology. Qual Res Psychol. 2006;3(2):77-101. doi:10.1191/1478088706qp063oa

41. Raykov T, Marcoulides GA. A First Course in Structural Equation Modeling. 2nd ed. Lawrence Erlbaum Associates, Publishers; 2006.

42. Ndubisi NO. Mindfulness, reliability, pre-emptive conflict handling, customer orientation and outcomes in Malaysia's healthcare sector. J Bus Res. 2012;65(4):537-546. doi:10.1016/j.jbusres.2011.02.019

43. Nguyen N. Service quality, customer perceived value and repurchase intention in $\mathrm{b} 2 \mathrm{~b}$ professional service context - the case of general insurance sector in Vietnam; 2019. Available from: https://hcmiu.edu. vn/wp-content/uploads/2020/08/PhD-DISSERTATION-NguyenXuan-Nhi-after-defense-compressed.pdf. Accessed October 8, 2021.

44. Hair JF, ed. Multivariate Data Analysis. 7th ed. Prentice Hall; 2010.

45. Bastemeijer CM, Boosman H, van Ewijk H, de Jong-verweij LM, Voogt L, Hazelzet J. Patient experiences: a systematic review of quality improvement interventions in a hospital setting. PROM. 2019;10:157-169. doi:10.2147/PROM.S201737

46. Wang H, Liang L, Du C, Wu Y. Implementation of online hospitals and factors influencing the adoption of mobile medical services in china: cross-sectional survey study. JMIR Mhealth Uhealth. 2021;9 (2):e25960. doi:10.2196/25960

47. Cambra-Fierro J, Gao L, Melero-Polo I. The power of social influence and customer-firm interactions in predicting non-transactional behaviors, immediate customer profitability, and long-term customer value. J Bus Res. 2021;125:103-119. doi:10.1016/j.jbusres.2020.12.013

48. Singh A, Gupta G, Viswanathan P. The role of social influence and e-service quality in impacting loyalty for online life insurance: a SEM-based study. IJBEX. 2019;1(1):1. doi:10.1504/ IJBEX.2019.10019249

49. Pentescu A, Cetină I, Orzan G. Social media's impact on healthcare services. Procedia Econ Finance. 2015;27:646-651. doi:10.1016/ S2212-5671(15)01044-8

50. Bornkessel A, Furberg R, Lefebvre RC. Social media: opportunities for quality improvement and lessons for providers - a networked model for patient-centered care through digital engagement. Curr Cardiol Rep. 2014;16(7):504. doi:10.1007/s11886-014-0504-5

51. Smailhodzic E, Hooijsma W, Boonstra A, Langley DJ. Social media use in healthcare: a systematic review of effects on patients and on their relationship with healthcare professionals. BMC Health Serv Res. 2016;16(1):442. doi:10.1186/s12913-016-1691-0

52. Kusumawati A, Rahayu KS. The effect of experience quality on customer perceived value and customer satisfaction and its impact on customer loyalty. TQM J. 2020;32(6):1525-1540. doi:10.1108/ TQM-05-2019-0150 


\section{Publish your work in this journal}

Patient Preference and Adherence is an international, peer-reviewed, open access journal that focusing on the growing importance of patient preference and adherence throughout the therapeutic continuum. Patient satisfaction, acceptability, quality of life, compliance, persistence and their role in developing new therapeutic modalities and compounds to optimize clinical outcomes for existing disease states are major areas of interest for the journal. This journal has been accepted for indexing on PubMed Central. The manuscript management system is completely online and includes a very quick and fair peer-review system, which is all easy to use. Visit http:// www.dovepress.com/testimonials.php to read real quotes from published authors. 